$\curvearrowright$

PERSONNEL ASSESSMENT

A N D DE CISIONS
Personnel Assessment and

Decisions

Volume 7

Issue 1 Special Issue: Understanding Effects of

Impression Management on Assessment

Article 8

Outcomes

2021

\title{
The Effect of Organizational Culture on Faking in the Job Interview
}

Damian Canagasuriam

Saint Mary's University - Canada

Nicolas Roulin

Saint Mary's University - Canada

Follow this and additional works at: https://scholarworks.bgsu.edu/pad

Part of the Human Resources Management Commons, Industrial and Organizational Psychology

Commons, and the Other Psychology Commons

How does access to this work benefit you? Let us know!

\section{Recommended Citation}

Canagasuriam, Damian and Roulin, Nicolas (2021) "The Effect of Organizational Culture on Faking in the Job Interview," Personnel Assessment and Decisions: Number 7 : Iss. 1 , Article 8.

DOI: https://doi.org/10.25035/pad.2021.01.008

Available at: https://scholarworks.bgsu.edu/pad/vol7/iss1/8

This Main Article is brought to you for free and open access by the Journals at ScholarWorks@BGSU. It has been accepted for inclusion in Personnel Assessment and Decisions by an authorized editor of ScholarWorks@BGSU. 


\title{
The Effect of Organizational Culture on Faking in the Job INTERVIEW
}

\author{
Damian Canagasuriam $^{1}$ and Nicolas Roulin ${ }^{1}$
}

\author{
1. Saint Mary's University - Canada
}

ABSTRACT

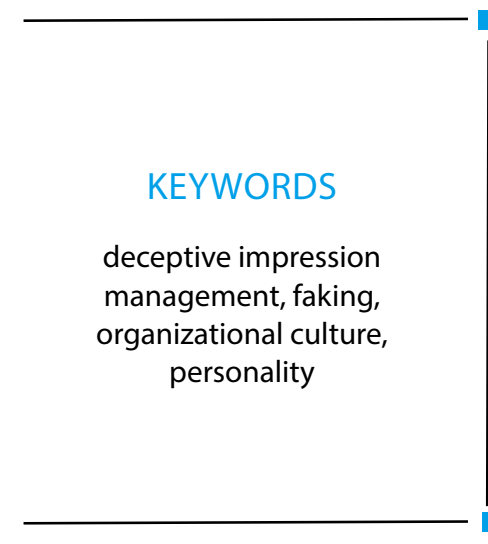

Deceptive impression management (i.e., faking) may alter interviewers' perceptions
of applicants' qualifications and, consequently, decrease the predictive validity of the
job interview. In examining faking antecedents, research has given little attention to
situational variables. Using a between-subjects experiment, this research addressed that
gap by examining whether organizational culture impacted both the extent to which
applicants faked and the manner in which they faked during a job interview. Analyses of
variance revealed that organizational culture did not affect the extent to which applicants
faked. However, when taking into account applicants' perceptions of the ideal candidate,
organizational culture was found to indirectly impact the manner in which applicants faked
their personality (agreeableness and honesty-humility). Overall, the findings suggest that
applicants may be able to fake their personality traits during job interviews to increase their
person-organization fit.

Organizational culture is a powerful phenomenon that can impact organizational effectiveness outcomes such as employee job satisfaction and organizational commitment (e.g., Al-Alawi et al., 2007; Hartnell et al., 2011; Stock et al., 2007). Although organizational culture's effects on current employees have received considerable attention, its effects on prospective employees have received relatively little attention. Job applicants gain information about organizations prior to completing selection procedures, and this knowledge influences their behavior during the selection process (e.g., Roulin \& Krings, 2020). However, little research has examined how organizational culture may influence applicant deceptive impression management (deceptive IM) during a job interview.

The present study addresses this gap and contributes to the interview faking literature by examining how organizational culture influences the extent to which applicants engage in faking and the manner in which they fake their personality during a job interview. In addition, it examines whether faking impacts interview performance. First, building on Roulin et al.'s (2016) model of faking, we examine whether a competitive organizational culture is associated with applicant self-reported faking (i.e., exaggerating and lying about qualifications) during a job interview. Second, building on earlier empirical work that examined applicant faking as an adaptive response (e.g., Roulin \& Krings, 2020), we examine whether applicants distort their person- ality in a manner dependent upon the culture of the hiring organization to increase their person-organization fit (see Kristof, 1996). Finally, drawing on Bangerter et al.'s (2012) signaling theory and on person-job fit, we examine whether the manner in which applicants fake their personality has an impact on their interview performance. The key elements we propose to examine in this study are summarized in the conceptual Figure 1.

\section{Deceptive Impression Management}

The personnel selection process can be described as an exchange of information between applicants and organizations (Bangerter et al., 2012). However, because applicants and organizations have imperfectly aligned motives, applicants may mislead interviewers by deceptively responding to interview questions to increase the perception that they are qualified for a position or that they match the organization's values. In interviews, deceptive IM or "faking" can be defined as "the conscious distortion of answers to the interview questions in order to obtain a better score on the interview and/or otherwise create favourable perceptions" (Levashina \& Campion, 2007, p. 1639).

In examining factors that influence applicant faking,

Corresponding author:

Damian Canagasuriam

Email: Damian.Canagasuriam@smu.ca 
FIGURE 1.

Conceptual Model of How Organizational Culture Affects Faking in Job Interviews

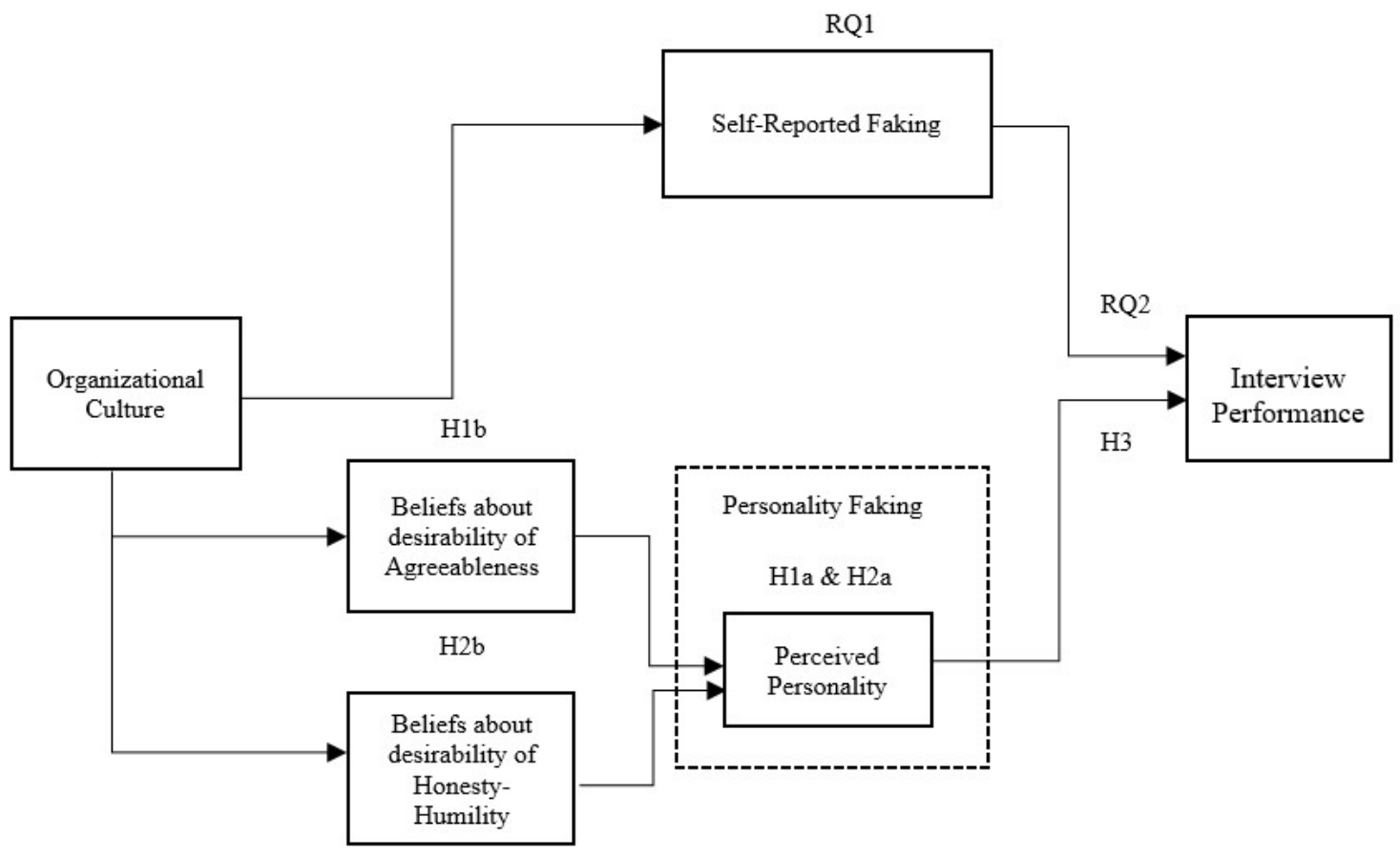

existing research has primarily focused on applicant characteristics (Buehl \& Melchers, 2017; Levashina \& Campion, 2007; Melchers et al., 2020; Roulin \& Krings, 2016). In relation to competition, several studies have found a strong positive relationship between applicants' competitive worldviews and faking in interviews (e.g., Roulin \& Krings, 2016; Schilling et al., 2020). However, research on the effect of situational variables on faking is sparser. A few recent studies (e.g., Bill et al., 2020; Ho et al., 2019; 2020; Roulin \& Krings, 2020) have examined how the competitiveness of the selection process, or an organization with a competitive climate or culture, influences faking. However, these studies have been limited to examinations of faking intentions and faking in personality tests, and none have examined actual personality faking in a job interview. This research aims to address that gap by examining the effect of organizational culture on both self-reported faking and personality faking in a job interview.

\section{Competitive Cultures and Applicant Faking}

Organizational culture can be defined as a pattern of values, beliefs, and expectations shared by an organization's members (Schwartz \& Davis, 1981). Competitiveness, whether embodied in environments (Stanne et al., 1999) or attitudes (Duckitt et al., 2002), reflects a belief that winning is extremely important and should be striven for at all costs. Thus, a competitive culture can be considered a pattern of values, beliefs, and expectations with success being valued above all else. On the contrary, collaboration can be defined as "a process of joint decision making among key stakeholders of a problem domain about that domain" (Gray, 1989, p. 11). It reflects a process of working together that prioritizes teamwork and communication (Batt \& Purchase, 2004) and member inclusion (Sergiovanni, 2004). Thus, a collaborative culture can be considered a pattern of values, beliefs, and expectations with an emphasis on teamwork and member inclusion.

Roulin et al.'s (2016) dynamic model of applicant faking highlights the importance of organizational culture as a situational faking antecedent. Their model proposes that applicants for an organization with a competitive culture may perceive more competition for the job and, thus, may be more motivated to fake to increase their chances of getting the job. However, recent empirical work (e.g., Bill et al., 2020; Ho et al., 2019, 2020; Roulin \& Krings, 2020) has reported mixed findings on the effect of competitive elements (e.g., competitive climates/cultures and selection processes) on faking (see Summary Table in Appendix G in the Supplemental Materials). For example, Ho et al. (2019, 2020) only found slightly higher interview faking intentions in a competitive (vs. less competitive) selection process and a competitive organizational climate $(d=.16-.21)$. In addition, Bill et al. (2020) found no difference to medium differences $(\eta=0.000-0.059)$ in interview faking intentions 
in competitive (vs. less competitive) selection processes across three studies. However, this research (i.e., Ho et al., 2019, 2020; Bill et al., 2020) examined faking intentions and not behaviors. In contrast, Roulin and Krings (2020) found that organizational culture was associated with actual faking behavior on a personality test, with participants reducing their scores on honesty-humility $(\mathrm{H}-\mathrm{H} ; d=.09$ $1.67)$ and agreeableness $(d=.21-1.05)$ when applying to a company with a competitive organizational culture. Yet, this research was not conducted in the interview context. Overall, the literature is unclear on whether a competitive organizational culture would increase faking behavior in an interview and, if so, to what extent. Given this, the following research question is proposed:

Research Question 1: Is a competitive organizational culture associated with higher levels of interview faking than both a collaborative organizational culture and when no culture information is provided?

\section{Personality Faking}

Organizational culture is relevant in personnel selection, in large part, because it guides how organizations determine a candidate's person-organization $(\mathrm{P}-\mathrm{O})$ fit $(\mathrm{Ca}-$ ble \& Judge, 1997). P-O fit can be described as the match between the characteristics of an individual and the characteristics of an organization (Muchinsky \& Monahan, 1987), and is associated with several positive outcomes such as organizational commitment, coworker satisfaction, and job satisfaction (Bretz \& Judge, 1994; Kristof-Brown et al., 2005).

Given the importance of $\mathrm{P}-\mathrm{O}$ fit, applicants may fake their attributes and qualifications in order to increase their perceived fit with an organization. Roulin and Krings (2020) found that participants distorted their responses on a personality test to increase their fit with the organizational culture of the hiring organization. For example, participants who applied to an organization with a competitive culture distorted their responses to appear less agreeable and less honest and humble. Although personality is often formally assessed via self-report measures, it is also one of the most frequently assessed constructs in the job interview (Huffcutt et al., 2001; Salgado \& Moscoso, 2002). Research has also suggested that personality can be faked in interviews (Van Iddekinge et al., 2005). Thus, if applicants are able to identify the desired personality profile, they can fake their mannerisms and responses to interview questions to increase their $\mathrm{P}-\mathrm{O}$ fit.

This study attempts to replicate Roulin and Krings' (2020) findings in a job interview. More precisely, given that competitive and collaborative organizational cultures have contrasting values, beliefs, and expectations, we examine whether applicants fake their personalities differently depending on the organizational culture. For example, because a competitive culture is associated with high employee trait competitiveness and the belief that success is a zero-sum game (Johnson \& Johnson, 1999), applicants may fake their personalities in a job interview to appear lower on agreeableness and $\mathrm{H}-\mathrm{H}$ to increase their perceived $\mathrm{P}-\mathrm{O}$ fit (Roulin \& Krings, 2020). On the other hand, because a collaborative culture is associated with low trait competitiveness and caring about the well-being of others (Fletcher $\&$ Nusbaum, 2008), they may fake to appear more agreeable and more honest and humble (Roulin \& Krings, 2020).

Hypothesis 1a: A competitive organizational culture, in comparison to a collaborative culture or when no culture information is provided, is associated with applicants being perceived as lower on agreeableness.

Hypothesis 1b: Applicants' beliefs about the extent to which the ideal candidate is agreeable partially mediate the relationship between organizational culture and perceived agreeableness.

Hypothesis 2a: A competitive organizational culture, in comparison to a collaborative culture or when no culture information is provided, is associated with applicants being perceived as lower on honesty-humility.

Hypothesis 2b: Applicants' beliefs about the extent to which the ideal candidate is honest and humble partially mediate the relationship between organizational culture and perceived honesty-humility.

\section{Faking and Interview Performance}

Faking is a significant issue because it may limit the extent to which the interview predicts job performance (Levashina \& Campion, 2006). Studies have demonstrated both positive and negative associations between applicants' use of faking during traditional job interviews and their interview scores (e.g., Melchers et al., 2020). However, although recent research has started to examine applicant faking in asynchronous video interviews (Basch, Melchers, Kegelmann, et al., 2020; Basch, Melchers, Kurz, et al., 2020), no research has examined whether (and how) self-reported faking or personality faking will result in higher or lower interview performance in an online context. Asynchronous video interviews are distinct from in-person interviews, and thus, faking may differ in this medium due to the unique interactions that may take place (Baker et al., 2020). We sought to address this gap and examine whether faking in an asynchronous video interview would be positively or negatively associated with performance ratings.

Research Question 2: Is applicant self-reported faking positively or negatively associated with their asynchronous video interview performance? 
In addition to extent of faking, the manner in which applicants fake their personality may also impact their performance. Agreeableness and $\mathrm{H}-\mathrm{H}$ have been found to predict performance domains such as task performance, contextual performance, and job involvement (Anand et al., 2015; Johnson et al., 2011; Liao \& Lee, 2009). Thus, applicants perceived as higher on agreeableness and H-H may receive higher evaluations from interviewers, regardless of the hiring organization's culture, because both traits may be important for job-related competencies such as teamwork and communication (see Fletcher \& Nusbaum, 2008). Thus, by faking their personality, specifically their agreeableness and $\mathrm{H}-\mathrm{H}$, applicants may increase their person-job fit and obtain higher performance ratings in interviews.

Hypothesis 3: Applicant faking to be perceived as more (a) agreeable and (b) honest and humble is evaluated more positively in interviews.

\section{METHOD}

\section{Power Analysis}

An a priori power analysis was conducted using $\mathrm{G}^{*}$ Power to determine the sample size necessary for achieving a power of .80. A medium-effect size of .30 (Cohen's $d$ ) was used for two reasons. First, it is the effect size found in previous work that examined the degree to which personality could be faked in interviews (Van Iddekinge et al., 2005). Second, an effect size of .30 represents a relatively conservative value between the somewhat small (e.g., Ho et al., 2020) and large effects (e.g., Roulin \& Krings, 2020) reported in previous work on competition and faking. The effect size of .30 resulted in a recommended sample size of 111 .

\section{Sample and Procedure}

One hundred and forty-six participants were recruited from the United States and Canada through the online crowdsourcing platform Prolific. Participants were removed if they did not pass the attention check (i.e., "please select agree"), if the video files with their responses did not work, or if their responses were inaudible/incomprehensible. This resulted in a final sample of 130 participants. The mean age

1 Based on the comments of anonymous reviewers, a post-hoc pilot study was conducted to confirm the effectiveness of the organizational culture manipulations. 59 MTurk participants rated the manipulations on variables such as the associated organizational culture's "competitiveness," "ability to win at all costs," "collaborativeness," and "emphasis on team success." In support of the manipulations, the competitive condition was rated as more competitive $(d=.1 .72)$ than the collaborative condition and as placing greater emphasis on winning at all costs $(d=1.53)$. In addition, the collaborative condition was rated as more collaborative $(d=2.63)$ than the competitive condition and as placing greater emphasis on team success $(d=1.24)$. was 39.41 years $(S D=12.62), 48.5 \%$ identified as female, and the majority was White (74.6\%). Participants had on average 7.3 years $(S D=7.95)$ of managerial experience. They had completed an average of $16.02(S D=22.57)$ traditional interviews and $0.73(S D=1.87)$ asynchronous video interviews, with most participants having never previously completed an asynchronous video interview.

Participants were randomly assigned to a competitive, collaborative, or control culture condition. They were instructed to imagine that they were interviewing for a business manager position. They were presented with a job description, an "about us" page (which included our culture manipulation; Appendix A in the Supplemental Materials), and then they answered six interview questions (Appendix B in the Supplemental Materials) on an asynchronous video interview platform. See Appendix C in the Supplemental Materials for a summary table of the post-hoc pilot results on the culture manipulation. ${ }^{1}$ To increase motivation, participants were informed that the top $10 \%$ of performers in the interview would receive $£ 5$ in addition to their base pay of $£ 4$. After completing the interview, participants were informed that the mock selection process was finished and that they should answer all of the remaining questions honestly. Participants then completed all the self-report measures.

\section{Measures}

Applicant perceptions. After the interview, participants completed five one-item (see Appendix C in the Supplemental Materials) measures assessing (a) the extent to which they believed the ideal candidate was agreeable; (b) the extent to which they believed the ideal candidate was honest and humble; (c) the extent to which they believed the hiring organization had a competitive culture (manipulation check); (d) the extent to which they believed the hiring organization had a collaborative culture (manipulation check); and (e) the degree to which they took the interview seriously.

Interview Faking Behavior Scale-Shortened (IFB-S). A revised version (slightly adapted to the asynchronous video interview context) of the 16-item IFB-S scale ( $\alpha=$ .90; Bourdage et al., 2018) was used to assess the extent to which participants deceptively responded to questions during the interview. A sample item is "I distorted my answers to emphasize what the organization was looking for."

Self-report personality. A relative percentile measure of personality (Dunlop et al., 2019) was used to assess the "honest" scores for agreeableness and H-H. The measure asked participants to indicate the percentile (using a slider scale from 1-100) in which they believe they fell for each of the four facets of agreeableness and the four facets of $\mathrm{H}-\mathrm{H}$. Cronbach's alpha for agreeableness and $\mathrm{H}-\mathrm{H}$ was .50 and .64, respectively, consistent with the findings of Dunlop et al. (2019), who reported values of .65 for agreeable and .69 for $\mathrm{H}-\mathrm{H}$. 
Perceived personality. Two graduate students blind to the experimental manipulation evaluated participants' personality using the same relative percentile measure (Dunlop et al., 2019). Raters watched each participants' interview responses and then assessed perceived agreeableness and $\mathrm{H}-\mathrm{H}$. This was used to capture potential personality faking (e.g., in comparison to the self-reported honest measure above). The final intraclass correlation coefficients (ICCs) were .55 for both traits. Given that personality can be difficult to assess in interviews (Van Iddekinge et al., 2005), these were considered appropriately high ICCs (LeBreton \& Senter, 2008). Further, meta-analyses have revealed that personality is difficult to accurately assess by observers with mean corrected interrater reliabilities ranging from .39 for openness to .52 for extraversion (Connelly \& Ones, 2010). Agreeableness, specifically, has been found to have an interrater reliability of .40 (Connelly \& Ones, 2010). Thus, the ICCs of .55 for agreeableness and $\mathrm{H}-\mathrm{H}$ traits are within range of what would be expected with observer assessments of personality. Internal consistency for agreeableness and $\mathrm{H}-\mathrm{H}$ was .94 and .91 , respectively. Averaged personality scores were used to test Hypothesis 1 and Hypothesis 2; however, to avoid common method variance (Campbell \& Fiske, 1959), Hypothesis 3 involved only perceived personality ratings from Rater 1.

Performance. The same two raters evaluated each participant on the extent to which they believed they would be a good fit for the position based on their overall performance during the interview in 5-point increments from 5-100. The final ICC for performance across all 130 participants was .65. The averaged performance scores were used to test Research Question 2; however, performance ratings from only Rater 2 were used for Hypothesis 3 to avoid common method variance.

\section{RESULTS}

\section{Attention and Manipulation Check}

The mean response to the interview seriousness item "I took the interview seriously" was $4.55(S D=.67)$. The item relied on a 1 (to no extent) to 5 (to a great extent) Likert scale, and thus, a mean of 4.55 suggested that most participants took the interview seriously. In addition, there were no differences between the competitive $(M=4.52, S D=$ $.74)$, collaborative $(M=4.56, S D=.63)$, and control group $(M=4.56, S D=.63)$ in terms of the degree to which they took the interview seriously $F(2,127)=.05, p=.95$. All participants also passed the attention check further suggesting that the results may be generalizable.

A one-way analysis of variance (ANOVA) was conducted to examine whether the culture condition was associated with differences in perceived organizational culture on "competitive" and "collaborative." The results confirmed that the about us page culture manipulation was effective:
Those in the competitive culture condition perceived their culture as more competitive $(M=4.50, S D=.80)$ than those in the collaborative condition $(M=3.68, S D=.85)$ and control condition $(M=3.59, S D=1.05), F(2,127)=14.14, p$ $<.01$. Similarly, those in the collaborative culture condition $(M=4.22, S D=.69)$ and control condition $(M=3.95, S D=$ .89) perceived their culture as more collaborative than those in the competitive condition $(M=3.19, S D=1.30), F(2$, $127)=12.62, p<.01$.

\section{Main Analyses}

Descriptive statistics and intercorrelations for the main study variables are presented in Table 1 . Regarding Research Question 1, ANOVA results showed no significant difference for self-reported faking in the interview between the three organizational culture conditions, $F(2,126)=$ $0.8, p=.92, \eta^{2}=.0013$. Means and standard deviations are presented in Table 2. This suggests that participants did not report faking more during the interview if they faced a competitive (vs. collaborative or control) organizational culture.

Three indicators were used to examine the effect of culture on personality faking similar to Roulin and Krings (2020): (a) perceived personality, (b) raw difference scores (perceived/faked personality vs. self-reported/honest personality), and (c) regression-adjusted difference scores (RADS, calculated by regressing the perceived personality scores in the interview on the self-report personality scores). ANOVA results are presented in Table 2. Results showed no difference between the three organizational culture conditions for either perceived agreeableness, $F(2,126)=.55$, $p=.58$, or perceived $\mathrm{H}-\mathrm{H}$ during the interview, $F(2,126)=$ $1.39, p=.25$. We also found no significant differences for raw difference scores for agreeableness, $F(2,127)=.18, p$ $=.84$ or $\mathrm{H}-\mathrm{H}, F(2,127)=.19, p=.83$. Finally, we found no significant difference for RADS for either perceived agreeableness, $F(2,127)=.64, p=.53$ or perceived $\mathrm{H}-\mathrm{H}, F(2$, $127)=1.04, p=.36$. Overall, the results did not support Hypothesis 1a and Hypothesis 2a and suggest that organizational culture does not directly impact how participants fake their personality during job interviews.

Mediated regression analyses were conducted using model four of Hayes' PROCESS macro with 5,000 samples for bootstrapped $95 \%$ confidence intervals to test Hypothesis $1 \mathrm{~b}$ and $2 \mathrm{~b}$. Results are presented in Table 3. We found a significant indirect effect of competitive culture (vs. collaborative culture or no culture information) on perceived agreeableness through beliefs about the extent to which the ideal candidate is agreeable, $b=-.3 .09, S E=1.25,95 \%$ CI $[-5.76,-.93]$. Similarly, there was a significant indirect effect of competitive culture on perceived $\mathrm{H}-\mathrm{H}$ through beliefs about the extent to which the ideal candidate is $\mathrm{H}-\mathrm{H}, b$ $=-2.05, S E=1.07,95 \% \mathrm{CI}=[-4.52,-.29]$. The significant mediations suggest a potential suppression effect may have 


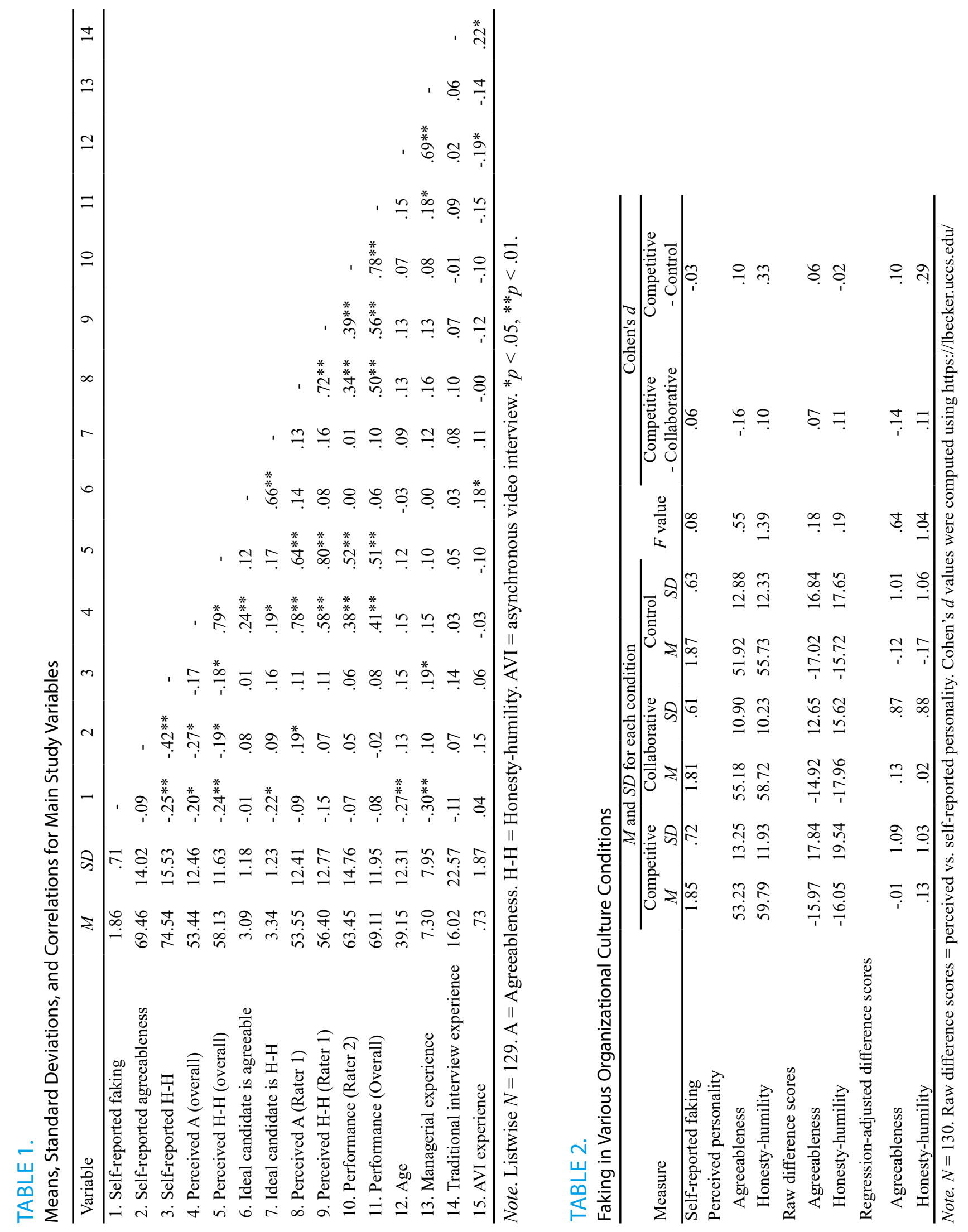




\section{TABLE 3.}

\section{Regressions for Tests of Mediation for Personality Hypotheses}

\begin{tabular}{|c|c|c|}
\hline & Ideal candidate is agreeable & Perceived A during interview \\
\hline \multicolumn{3}{|l|}{ Step 1: Agreeableness } \\
\hline Constant & $3.54 * *(.17)$ & $51.92 * *(1.94)$ \\
\hline Competitive culture & $-1.04 * *(.23)$ & $1.31(2.64)$ \\
\hline Collaborative culture & $-.15(.24)$ & $3.26(2.64)$ \\
\hline$R^{2}$ & .16 & .01 \\
\hline \multicolumn{3}{|l|}{ Step 2} \\
\hline Constant & & $41.39 * *(3.91)$ \\
\hline Competitive culture & & $4.40(2.75)$ \\
\hline Collaborative culture & & $3.70(2.66)$ \\
\hline Ideal candidate is agreeable & & $2.98 * *(.97)$ \\
\hline$R^{2}$ & & .08 \\
\hline \multicolumn{3}{|l|}{ Indirect effects } \\
\hline Competitive culture $\rightarrow$ Ideal A $\rightarrow$ Faking & & $-3.09 *(1.25) 95 \%$ CI $[-5.76,-.93]$ \\
\hline \multirow[t]{2}{*}{ Collaborative culture $\rightarrow$ Ideal A $\rightarrow$ Faking } & & $-.44(.66) 95 \%$ CI $[-1.81, .86]$ \\
\hline & Ideal candidate is $\mathrm{H}-\mathrm{H}$ & Perceived $\mathrm{H}-\mathrm{H}$ during interview \\
\hline \multicolumn{3}{|l|}{ Step 1: Honesty-humility } \\
\hline Constant & $3.61 * *(.18)$ & $55.73 * *(1.80)$ \\
\hline Competitive culture & $-.88 * *(.24)$ & $4.06(2.46)$ \\
\hline Collaborative culture & $.20(.25)$ & $2.99(2.55)$ \\
\hline$R^{2}$ & .15 & .02 \\
\hline \multicolumn{3}{|l|}{ Step 2} \\
\hline Constant & & $47.34 * *(3.62)$ \\
\hline Competitive culture & & $6.11 *(2.52)$ \\
\hline Collaborative culture & & $2.53(2.58)$ \\
\hline Ideal candidate is $\mathrm{H}-\mathrm{H}$ & & $2.32 * *(.50)$ \\
\hline$R^{2}$ & & .07 \\
\hline \multicolumn{3}{|l|}{ Indirect effects } \\
\hline Competitive culture $\rightarrow$ Ideal $\mathrm{H}-\mathrm{H} \rightarrow$ Faking & & $-2.05 *(1.07) 95 \% \mathrm{CI}[-4.52,-.29]$ \\
\hline Collaborative culture $\rightarrow$ Ideal H-H $\rightarrow$ Faking & & $.45(.55) 95 \%$ CI $[-.48,1.74]$ \\
\hline
\end{tabular}

Note. Listwise $N=130$. Values are unstandardized b-values with standard errors in parentheses. Competitive culture $=$ competitive culture vs others (coded -1, 0.5, 0.5 for competitive, control, and collaborative, respectively). Collaborative culture $=$ collaborative culture vs. others (coded $0.5,0.5,-1) . \mathrm{H}-\mathrm{H}=$ honesty-humility. Ideal $\mathrm{A}=$ extent to which the ideal candidate is agreeable. Ideal $\mathrm{H}-\mathrm{H}=\mathrm{extent}$ to which the ideal candidate is H-H. All analyses had $95 \%$ bootstrapped confidence intervals with 5000 samples. * $p<.05 ; * * p<.01$.

obfuscated the impact of culture on faking in the ANOVAs. Specifically, there was a positive direct effect of competitive organizational culture on perceived/faked agreeableness $(b=4.40, p=.11)$ and perceived/faked $\mathrm{H}-\mathrm{H}(b=6.11$, $p=.02)$. However, there was a negative indirect effect, with a negative and significant relationship between competitive culture and beliefs about the extent to which the ideal candidate is agreeable and honest/humble (agreeableness: $b=$ $-1.04, p<.01$; H-H: $b=-.88, p<.01$ ), and a positive and significant relationship between the extent to which the ideal candidate is agreeable and honest/humble, and perceived agreeableness and $\mathrm{H}-\mathrm{H}$ during the interview (agreeableness: $b=1.31, p>.05 ; \mathrm{H}-\mathrm{H}: b=6.11, p<.05)$. This finding suggests that the true relationship between organizational culture and faking may have been suppressed in the ANOVAs, and that it only became clear once the perceived ideal candidate personality was considered. Overall, our results suggest that applicants facing a more competitive organizational culture perceived the ideal personality to involve lower agreeableness and $\mathrm{H}-\mathrm{H}$, and faked to be perceived as lower on agreeableness and $\mathrm{H}-\mathrm{H}$ to increase their $\mathrm{P}-\mathrm{O}$ fit.

A linear regression was conducted to examine the relationship between self-reported faking and interview performance (Research Question 2). We found no signif- 
icant relationship, $b=-1.77, S E=1.85,95 \% \mathrm{CI}=[-5.27$, 1.74]. Next, we used a series of regressions to examine the relationship between personality faking and performance using perceived personality, raw difference scores, and RADS (Hypothesis 3). Both perceived agreeableness $(b=$ $.32, S E=.08,95 \% \mathrm{CI}=[.15, .49])$ and perceived $\mathrm{H}-\mathrm{H}(b$ $=.37, S E=.08,95 \%$ CI $[.22, .51])$ were positively related to interview performance. Similarly, regressions with raw difference scores revealed that applicants who faked being more agreeable $(b=.14, S E=.07,95 \%$ CI $[.01, .29])$ and more H-H $(b=.14, S E=.06,95 \%$ CI $[.03, .24])$ received higher performance ratings. Finally, regressions with RADS confirmed the relationship between perceived agreeableness $(b=3.96, S E=1.00,95 \%$ CI $[2.09,5.83])$ and interview performance, and perceived H-H $(b=4.65, S E=.99,95 \%$ CI $[2.60,6.57]$ and interview performance.

\section{DISCUSSION}

\section{Theoretical and Practical Contributions}

Overall, the findings from this study help demonstrate how organizational culture may influence applicant faking in the job interview and how personality faking may affect interview performance. First, whether an applicant was applying to an organization with a competitive, collaborative, or an undisclosed culture did not affect the extent to which they reported faking during the job interview. Thus, our findings did not provide support for Roulin et al.'s (2016) model, which posited that a competitive organizational culture would increase overall faking. The findings also differ from those of Bill et al. (2020) and Ho et al. (2019, 2020), which found that perceptions of competitive (vs. low/noncompetitive) situations and climates led to slightly increased faking intentions. This discrepancy suggests that applicants who face a competitive organizational culture or climate might be willing to fake but are ultimately unable to engage in actual faking behaviors in an interview. Alternatively, applicants may ascribe too much importance to the competitiveness of an organizational culture when reporting their willingness to fake in a potential interview without considering other factors (e.g., perceived cost of getting caught faking, their lack of the required skills or abilities to fake) that may impact their actual faking behavior.

Second, a competitive organizational culture was associated with lower levels of both perceived agreeableness and $\mathrm{H}-\mathrm{H}$, but only when considering the role of applicants' beliefs about the ideal candidate's personality. Although organizational culture did not have an overall effect on personality faking, the inclusion of applicants' perceptions of the ideal personality provided support for Roulin and Krings' (2020) assertion that applicants use information about an organization's culture to infer the desired applicant profile and then fake to reflect the sought-after characteristics. In our study, applicants facing a more competitive organizational culture identified that the ideal personality profile would involve lower agreeableness and lower $\mathrm{H}-\mathrm{H}$, and were ultimately perceived as lower on agreeableness and $\mathrm{H}-\mathrm{H}$ by raters. This suggests that applicants adjusted their behavior to appear lower on agreeableness and $\mathrm{H}-\mathrm{H}$ in the interview. This finding demonstrates that the effect of organizational culture on faking is not limited to personality tests (see Roulin \& Krings, 2020) but that organizational culture can also affect faking in job interviews.

Third, applicant self-reported faking was unrelated to interview performance. This suggests that applicants may have found it difficult to strategically fake to increase their perceived $\mathrm{P}-\mathrm{O}$ fit. This increased difficulty to strategically fake may have been due to the structured nature of the asynchronous video interview and the reduced potential for deceptive ingratiation (e.g., because the asynchronous video interview did not involve an actual interviewer as a target for ingratiation). However, the degree to which applicants faked to be perceived as more agreeable and honest and humble was positively related to performance ratings. This finding is practically important because interviewers often attempt to gauge applicants' personalities during interviews and also use evaluations of personality to assess person-job fit (see Caldwell \& Burger, 1998; Chen et al., 2011). Agreeableness and $\mathrm{H}-\mathrm{H}$ are generally viewed as traits that help increase job performance (Anand et al., 2015; Johnson et al., 2011; Liao \& Lee, 2009), and it appears that perceptions of applicants' agreeableness and H-H were associated with more positive evaluations of applicants.

A key practical implication arises from the finding that higher perceived agreeableness and $\mathrm{H}-\mathrm{H}$ were associated with better interviewer ratings. Specifically, the finding may lead to applicants making a stronger effort to fake agreeableness and $\mathrm{H}-\mathrm{H}$ because they believe that interviewers are likely to perceive these traits as indicative of future job performance. This finding is interesting given that the interview was for a business manager position. Meta-analytical evidence suggests that applicants typically fake to appear more agreeable much more for nonmanagerial than for managerial positions (Birkeland et al., 2006). This study suggests that applicants may benefit from displaying higher levels of agreeableness (and $\mathrm{H}-\mathrm{H}$ ) for managerial positions as well.

\section{Limitations and Future Research Directions}

This research has a number of limitations that suggest directions for future faking research. First, our study involved a mock (i.e., low stakes) asynchronous video interview with a sample of Prolific respondents. Although this approach was relevant given our experimental design, future research should examine if stronger effects are observed when stakes are higher (with applicants for an actual job) and/or when using an in-person interview.

Second, our study included a somewhat limited sample 
size. Although we determined the appropriate sample size for this study a priori using a power analysis, we relied on a Cohen's $d$ effect size of .30. This value was believed to be a conservative effect size based on prior research on personality and interview faking. However, because some research (i.e., Ho et al., 2019, 2020) suggests that the effect sizes for situational effects (e.g., competitive climates) on faking can be relatively small (e.g., .08 - .19), future research should thus examine the effect of culture on faking in interviews using a larger sample size.

Third, we did not use behaviorally anchored rating scales (BARS) to evaluate interview performance but relied on an overall 1-100 assessment. Although this might reflect the unstructured way many interviews are conducted and rated in practice, this may have resulted in less valid and reliable assessments of interview performance (Hollwitz \& Wilson, 1993; Kutcher \& Bragger, 2004). Future research should use BARS for interview questions.

Fourth, in most of the personality literature, faking is captured as the difference in self-reported personality between an honest and faking/applicant condition. In contrast, this study conceptualized personality faking as the difference between applicants' self-reported personality (honest condition) and their personality as perceived by raters (faking condition). Yet, the honest measure of personality was collected immediately after the interview, where applicants might have faked, possibly leading to some carryover effects that might have diluted the faking effects. In addition, the perceived personality ratings had low-to-medium interrater reliability, suggesting that personality may not have been easy to assess. As such, the nonsignificant relationships between organizational culture and personality faking (when the mediating variables were excluded) may be partially due to this low reliability. Although observer-report personality measures typically have low reliabilities (Connelly \& Ones, 2010), the use of the relative percentile method (Dunlop et al., 2019) in favor of a more established measure such as the observer-report HEXACO (Lee \& Ashton, 2006) may have resulted in the lower reliabilities. The relative percentile method was chosen because of its relative ease of administration with raters only having to provide an assessment of each participants' personality at the facet level (e.g., sincerity). Although the observer-report relative percentile method yielded reliabilities similar to those found for the observer-report HEXACO, the self-report relative percentile method yielded reliabilities lower than those typically found for the self-report HEXACO (Lee $\&$ Ashton, 2004). The reduced reliability of the self-report relative percentile method could have reduced our faking effect. The relative percentile method relies on a comparison group, which also might restrict variability for personality scores and reduce the amount of faking captured by raw difference scores or RADS. Thus, future research should examine whether a direct relationship and a stronger indirect relationship exists between organizational culture and personality faking with the use of more established personality measures such as the self-report and observer-report HEXACO.

In terms of personality faking, future research should utilize a more systematic process for evaluating participants' personalities. This may include creating lists of verbal behaviors that suggest the presence of the various personality trait facets. Relatedly, we found that certain facets (e.g., patience) had particularly low ICCs. Although we relied on the facets and definitions from the HEXACO framework, this suggests that not all four facets for each trait could be effectively assessed during the asynchronous video interview. Future research should examine whether certain facets are harder to assess (particularly during asynchronous video interviews) and focus on the facets that are more reliably assessed. Additionally, future research should investigate whether organizational culture leads to differences in personality faking during an interview by examining personality at the facet level rather than the trait level.

\section{REFERENCES}

Al-Alawi, Al., Al-Marzooqi, N., \& Mohammed, Y. (2007). Organizational culture and knowledge sharing: Critical success factors. Journal of Knowledge Management, 11(2), 22-42. https://doi.org/10.1108/13673270710738898

Anand, S., Vidyarthi, P., Singh, S., \& Ryu, S. (2015). Family interference and employee dissatisfaction: Do agreeable employees better cope with stress? Human Relations, 68(5), 691-708.

Baker, D. A., Burns, D. M., \& Reynolds Kueny, C. (2020). Just sit back and watch: Large disparities between video and faceto-face interview observers in applicant ratings. International Journal of Human-Computer Interaction, 36(20), 1968-1979.

Bangerter, A., Roulin, N., \& König, C. J. (2012). Personnel selection as a signaling game. Journal of Applied Psychology, 97(4), 719-738. https://doi.org/10.1037/a0026078

Basch, J. M., Melchers, K. G., Kegelmann, J., \& Lieb, L. (2020). Smile for the camera! The role of social presence and impression management in perceptions of technology-mediated interviews. Journal of Managerial Psychology. https:// doi.org/10.1007/s10869-020-09714-3

Basch, J. M., Melchers, K. G., Kurz, A., Krieger, M., \& Miller, L. (2020). It takes more than a good camera: Which factors contribute to differences between face-to-face interviews and videoconference interviews regarding performance ratings and interviewee perceptions? Journal of Business and Psychology. Advanced online publication. https://link.springer.com/ article/10.1007/s10869-020-09714-3

Batt, P. J., \& Purchase, S. (2004). Managing collaboration within networks and relationships. Industrial Marketing Management, 33(3), 169-174.

Bill, B., Melchers, K. G., Buehl, A.-K., \& Wank, S. (2020). An investigation of situational and dispositional antecedents of fak- 
ing intentions in selection interviews. Frontiers in Psychology, 11, 2034.

Birkeland, Manson, T, Kisamore, J, Brannick, M, \& Smith, M. (2006). A meta-analytic investigation of job applicant faking on personality measures. International Journal of Selection and Assessment, 14, 317-335. https://doi.org/10.1111/ j.1468-2389.2006.00354.x

Bourdage, J. S., Roulin, N., \& Tarraf, R. (2018). "I (might be) just that good": Honest and deceptive impression management in employment interviews. Personnel Psychology, 71, 597632. https://doi.org/10.1111/peps.12285

Bretz, R. D., \& Judge, T. A. (1994). The role of human resource systems in job applicant decision processes. Journal of Management, 20(3), 531-551. https://doi. org/10.1177/014920639402000301

Buehl, A.-K., \& Melchers, K. G. (2017). Individual difference variables and the occurrence and effectiveness of faking behavior in interviews. Frontiers in Psychology, 8(686). https:// doi.org/10.3389/fpsyg.2017.00686

Cable, D. M., \& Judge, T. A. (1997). Interviewers' perceptions of person-organization fit and organizational selection decisions. Journal of Applied Psychology, 82(4), 546.

Caldwell, D. F., \& Burger, J. M. (1998). Personality characteristics of job applicants and success in screening interviews. Personnel Psychology, 51, 119-136.

Campbell, D. T., \& Fiske, D. W. (1959). Convergent and discriminant validation by the multitrait-multimethod matrix. Psychological Bulletin, 56(2), 81.

Chen, C., Huang, Y., Huang, T., \& Liu, I. (2011). The mediating processes linking applicant personality traits and interviewer evaluation. International Journal of Selection and Assessment, 19(3), 287-300.

Connelly, B. S., \& Ones, D. S. (2010). An other perspective on personality: Meta-analytic integration of observers' accuracy and predictive validity. Psychological Bulletin, 136(6), 1092-1122. https://doi.org/10.1037/a0021212

Duckitt, J., Wagner, C., Du Plessis, I., \& Birum, I. (2002). The psychological bases of ideology and prejudice: Testing a dual process model. Journal of Personality and Social Psychology, 83(1), 75. https://doi.org/10.1037/0022-3514.83.1.75

Dunlop, P. D., Holtrop, D., Schmidt, J. A., \& Butcher, S. B. (2019). Investigating relative and absolute methods of measuring HEXACO personality using self-and observer reports. Zeitschrift Für Psychologie, 227(3), 218-224. https://doi. org/10.1027/2151-2604/a000380

Fletcher, T. D., \& Nusbaum, D. N. (2008). Trait competitiveness as a composite variable: Linkages with facets of the bigfive. Personality and Individual Differences, 45(4), 312-317. https://doi.org/j.paid.2008.04.020

Gray, B. (1989). Collaborating: Finding common ground for multiparty problems. Jossey-Bass.

Hartnell, C. A., Ou, A. Y., \& Kinicki, A. (2011). Organizational culture and organizational effectiveness: A meta-analytic investigation of the competing values framework's theoretical suppositions. Journal of Applied Psychology, 96(4), 677-694. https://doi.org/10.1037/a0021987

Ho, J. L., Powell, D. M., Barclay, P., \& Gill, H. (2019). The influence of competition on motivation to fake in employment interviews. Journal of Personnel Psychology, 18(2), 95-105. https://doi.org/10.1027/1866-5888/a000222

Ho, J. L., Powell, D. M., Spence, J. R., \& Perossa, A. (2020). Willingness to fake: Examining the impact of competitive climate and hiring situations. International Journal of Selection and Assessment. Advance online publication. https://doi. org/10.1111/ijsa.12288

Hollwitz, J., \& Wilson, C. E. (1993). Structured interviewing in volunteer selection. Journal of Applied Communication Research, 21(1), 41-52.

Huffcutt, A. I., Conway, J. M., Roth, P. L., \& Stone, N. J. (2001). Identification and meta-analytic assessment of psychological constructs measured in employment interviews. Journal of Applied Psychology, 86, 897-913.

Johnson, D., \& Johnson, R. (1999). Making cooperative learning work. Theory Into Practice, 38(2), 67-73. https://doi. org/10.1080/00405849909543834

Johnson, M. K., Rowatt, W. C., \& Petrini, L. (2011). A new trait on the market: Honesty-humility as a unique predictor of job performance ratings. Personality and Individual Differences, 50(6), 857-862.

Kristof, A. L. (1996). Person-organization fit: An integrative review of its conceptualizations, measurement, and implications. Personnel Psychology, 49(1), 1-49. https://doi. org/10.1111/j.1744-6570.1996.tb01790.x

Kristof-Brown, A. L., Zimmerman, R. D., \& Johnson, E. C. (2005). Consequences of individual's fit at work: A meta-analysis of person-job, person-organization, person-group, and person-supervisor fit. Personnel Psychology, 58(2), 281-342. https://doi.org/10.1111/j.1744-6570.2005.00672.x

Kutcher, E. J., \& Bragger, J. D. (2004). Selection interviews of overweight job applicants: Can structure reduce the bias? Journal of Applied Social Psychology, 34(10), 1993-2022.

LeBreton, J. M., \& Senter, J. L. (2008). Answers to 20 questions about interrater reliability and interrater agreement. Organizational Research Methods, 11(4), 815-852. https://doi. org/10.1177/1094428106296642

Lee, K., \& Ashton, M. C. (2004). Psychometric properties of the HEXACO Personality Inventory. Multivariate Behavioral Research, 39(2), 329-358. https://doi.org/10.1207/ s15327906mbr3902_8

Lee, K., \& Ashton, M. C. (2006). Further assessment of the HEXACO Personality Inventory: Two new facet scales and an observer report form. Psychological Assessment, 18(2), 182-191. https://doi.org/10.1037/1040-3590.18.2.182

Levashina, J., \& Campion, M. A. (2006). A model of faking likelihood in the employment interview. International Journal of Selection and Assessment, 14, 299-316. https://doi. org/10.1111/j.1468-2389.2006.00353.x

Levashina, J., \& Campion, M. A. (2007). Measuring faking in the employment interview: Development and validation of an interview faking behavior scale. Journal of Applied Psychology, 92, 1638-1656. https://doi.org/10.1037/00219010.92.6.1638

Liao, C., \& Lee, C. (2009). An empirical study of employee job involvement and personality traits: The case of Taiwan. International Journal of Economics and Management, 3(1), 22-36.

Melchers, K. G., Roulin, N., \& Buehl, A. (2020). A review of applicant faking in selection interviews. International Journal of 
Selection and Assessment, 28(2), 123-142.

Muchinsky, P. M., \& Monahan, C. J. (1987). What is person-environment congruence? Supplementary versus complementary models of fit. Journal of Vocational Behavior, 31(3), 268-277. https://doi.org/10.1016/0001-8791(87)90043-1

Roulin, N., \& Krings, F. (2016). When winning is everything: The relationship between competitive worldviews and job applicant faking. Applied Psychology, 65(4), 643-670.

Roulin, N., \& Krings, F. (2020). Faking to fit in: Applicants' response strategies to match organizational culture. Journal of Applied Psychology, 105(2), 130.

Roulin, N., Krings, F., \& Binggeli, S. (2016). A dynamic model of applicant faking. Organizational Psychology Review, 6(2), 145-170. https://doi.org/10.1177/2041386615580875

Salgado, J. F., \& Moscoso, S. (2002). Comprehensive meta-analysis of the construct validity of the employment interview. European Journal of Work and Organizational Psychology, 11(3), 299-324.

Schilling, M., Sparfeldt, J. R., Becker, N., Engel, M., Levacher, J., Sebastian, T. F., Schäfer, J., Schwabe, S., \& König, C. J. (2020). Is it enough to be willing to win or do you have to be smart? The relationship between competitive worldviews, cognitive abilities, and applicant faking in personality tests. International Journal of Selection and Assessment, 28(3), 264-282.

Schwartz, H., \& Davis, S. M. (1981). Matching corporate culture and business strategy. Organizational Dynamics, 10(1), 30-48. https://doi.org/10.1016/0090-2616(81)90010-3

Sergiovanni, T. (2004). Collaborative cultures and communities of practice. Principal Leadership, 5(1), 48-52.

Stanne, M. B., Johnson, D. W., \& Johnson, R. T. (1999). Does competition enhance or inhibit motor performance: A meta-analysis. Psychological Bulletin, 125(1), 133-154. https:// doi.org/10.1037/0033-2909.125.1.133

Stock, G. N., McFadden, K. L., \& Gowen, C. R. (2007). Organizational culture, critical success factors, and the reduction of hospital errors. International Journal of Production Economics, 106(2), 368-392. https://doi.org/10.1016/j.ijpe.2006.07.005

Van Iddekinge, C. H., Raymark, P. H., \& Roth, P. L. (2005). Assessing personality with a structured employment interview: Construct-related validity and susceptibility to response inflation. Journal of Applied Psychology, 90(3), 536-552. https://doi.org/10.1037/0021-9010.90.3.536

RECEIVED 09/29/20 ACCEPTED 03/17/21 